\title{
Asymmetric effects of monetary policy shocks on economic performance: empirical evidence from Turkey
}

\section{Volkan Ülke \& M. Hakan Berument}

To cite this article: Volkan Ülke \& M. Hakan Berument (2016) Asymmetric effects of monetary policy shocks on economic performance: empirical evidence from Turkey, Applied Economics Letters, 23:5, 353-360, DOI: 10.1080/13504851.2015.1073836

To link to this article: https://doi.org/10.1080/13504851.2015.1073836

Published online: 05 Aug 2015.

Submit your article to this journal ¿

Џ Article views: 346

Q View related articles ¿

View Crossmark data ¿ 


\title{
Asymmetric effects of monetary policy shocks on economic performance: empirical evidence from Turkey
}

\author{
Volkan Ülke and M. Hakan Berument ${ }^{\mathrm{b}}$ \\ aFaculty of Economics, International Burch University, Sarajevo, Bosnia and Herzegovina; ${ }^{b}$ Department of Economics, Bilkent University, \\ Ankara, Turkey
}

\section{ABSTRACT}

This study investigates the asymmetric effects of monetary policy shocks on the macroeconomic variables of exchange rate, output and inflation for an emerging economy - Turkey - by using monthly data between 1990 and 2014. We employ the innovative nonlinear vector autoregressive model of Kilian and Vigfusson (2011), which allows us to observe the effect of different stances (tight or loose) and different sizes (small or large) of monetary policy actions. Our empirical evidence reveals that tight monetary policy, which, in this case, is captured with a positive shock to interest rate, decreases exchange rate, output and prices, as economic theory suggests. Loose monetary policy, which is captured with a negative shock to interest rate, has the opposite effect on these variables. However, the effects of loose monetary policy are weaker than the effects of tight monetary policy because loose monetary policy shocks are less effective than tight monetary policy shocks. Moreover, as the magnitude of a shock increases, the difference between the effects of tight and loose monetary policy policies also increases.

\section{KEYWORDS}

Monetary policy; asymmetry; nonlinear VAR models

JEL CLASSIFICATION

E52; E58; C32

\section{Introduction}

The asymmetric effects of monetary policy on macroeconomic variables have been recognized since the Great Depression. ${ }^{1}$ Friedman (1968) views monetary policy as a string, suggesting that it can be pulled to stop inflation but cannot be pushed to halt recession. This approach is supported by empirical evidence in the literature. ${ }^{2}$ Furthermore, empirical evidence for the hypothesis that tight monetary policy shocks are more effective for controlling macroeconomic variables than loose monetary policy shocks has been documented for developed and emerging economies. ${ }^{3}$ The effect of monetary policy is an important issue for central banks. Hence, investigating the asymmetric effects of monetary policy is an important undertaking. The aim of this study is to examine the asymmetric effects of monetary policy on a set of macroeconomic variables, i.e. exchange rate, output and inflation for an emerging economy - Turkey - by using the nonlinear vector autoregressive (VAR) model introduced by Kilian and Vigfusson (2011).

The seminal studies on the asymmetric effects of monetary policy on macroeconomic variables are theoretically based on the standard Keynesian model with a convex aggregate supply curve, credit constraint models and menu cost models. The standard Keynesian model with a convex aggregate supply curve implies that loose monetary policy shocks should be neutral, whereas tight monetary policy shocks should be nonneutral because the aggregate supply curve is upwardly flexible and wages are downwardly sticky (Cover 1992). Credit constraint models propose that tight policy makes banks reluctant to lend money and they would thus raise loan rates for borrowers. Therefore, a tight monetary policy is effective for growing the economy that is associated with a strong demand for credit (Morgan 1993). The menu cost model presents a possible explanation for the asymmetric adjustment of

CONTACT: M. Hakan Berument berument@bilkent.edu.tr

${ }^{1}$ See Morgan (1993) for a history of asymmetry.

${ }^{2}$ Caballero and Engel (1992), Ball and Mankiw (1994), Ravn and Sola (1996), Weise (1999), Garcia and Schaller (2002), Lo and Piger (2005), Tan and Habibullah (2007), Vašíček (2012), Sznajderska (2014) and Georgiadis (2015) present the asymmetric effects of monetary policy.

${ }^{3}$ Studies that suggest that a tight monetary policy is more effective for the United States include DeLong and Summers (1988), Cover (1992), Morgan (1993), Rhee and Rich (1995), Garibaldi (1997), Karras and Stokes (1999) and Karras (2013); for Europe include Karras and Stokes (1999); for Taiwan include Shen (2000); and for Pakistan include Zakir and Malik (2013).

() 2015 Taylor \& Francis 
nominal prices - a positive trend in inflation causes firms' relative prices to decline automatically between price adjustments. In this environment, shocks that raise firms' desired prices trigger larger price responses than shocks that lower desired prices. Conversely, the impact of a tight monetary policy would be more obvious (Ball and Mankiw 1994; Bernanke and Gertler 1986). In addition to these studies, various empirical studies introduce the size of monetary policy shocks (small or large), business cycle circumstance and policy-maker's reaction as reasons for the asymmetric effects of different (tight or loose) monetary policy actions. Ball and Romer (1989, 1990), by applying the menu cost model, and Ravn and Sola (1996), by using the standard Keynesian model, present the notion that small monetary policy shocks are more effective on output than large ones. All the authors suggest that firms will be reluctant to change prices under a 'small' monetary shock but will be willing to do so under a 'big' monetary shock. To assess the effect of a monetary policy shock, we gathered data from Turkey, a country that provides a suitable laboratory environment in which to explore this issue. First, exchange rate, interest rate, output and inflation volatilities are high in Turkey: for the sample we consider, the standard errors of exchange rate depreciation (the basket consists of 0.5 USD + 0.5 EUR), interest rate, monthly industrial output growth and monthly percentage change in the consumer price index (CPI) are $32464.13,49.01,8.62$ and 2.54, respectively. For the same period, the same variables for the US are 10.40 (trade-weighted US Dollar index), 2.23, 0.65 and 0.268 , respectively. Turkey's high volatility decreases the type-II error (not rejecting the null when it is false). Second, Turkey is a small open-market economy and the variable of interest responds to economic fundamentals rather than the variables (such as the exchange rate set by the policy authority).

The contributions of the article are twofold. First, ours is the first article that assesses the asymmetric effect of monetary policy shocks through multivariate analyses at a given time rather than assessing a single variable; thus, we eliminate a possible left-outvariable bias problem. Second, it is also the first study that assesses the asymmetric effect of monetary policy on exchange rate and output. The empirical evidence reveals that (1) a tight monetary policy is more effective than a loose monetary policy and (2) the bigger is the change in the stance of monetary policy, the higher will be the effect of monetary policy on economic variables.

The rest of the article is structured as follows: the 'Data' section presents the data, the 'Methodology' section introduces the econometric methodology, the 'Empirical results' section discusses the empirical evidence and the 'Conclusion' section concludes.

\section{Data}

To investigate the asymmetric effect of monetary policy on economic activity, we gathered monthly data from January 1990 to July 2014. The variables list employed in the VAR model is comprised of exchange rate, interest rate, output and price. Exchange rate is the Turkish Lira value of the exchange rate basket, consisting of 0.5 USD +0.5 EUR. Interest rate is the overnight interbank interest rate. Output is industrial production and price is the CPI. All the variables used in the analyses are in their logarithmic forms except for interest rate, for which we enter the analyses as they are. The VAR methodology that we employ requires the series to be stationary. In order to test the data's integration properties, we use augmented DickeyFuller and Phillips-Perron unit root tests (see Table 1). These tests show that all the transformed series are stationary at $1 \%$ significance level, which means that the VAR model can be employed to satisfaction. Based on the Schwarz information criterion, the lag order is selected as 1 . Thus, the variables enter into the analysis with their second differences, except for interest rate, which enters with its first difference. All Turkish data were gathered from the Central Bank of the Republic of Turkey's (CBRT's) electronic data delivery system (EDDS); after 2000, the interest rate

Table 1. Unit root tests.

\begin{tabular}{lccccc}
\hline & \multicolumn{2}{c}{ A: Intercept } & & \multicolumn{2}{c}{ B: Intercept with Trend } \\
\cline { 2 - 3 } \cline { 5 - 6 } & ADF & PP & & ADF & PP \\
\hline Interest rate $^{\mathrm{a}}$ & $-11.54^{* * * *}$ & $-319.08^{* * * *}$ & & $-11.52^{* * *}$ & $-318.71^{* * *}$ \\
Exchange rate $^{\mathrm{b}}$ & $-13.04^{* * *}$ & $-60.87^{* * *}$ & & $-13.01^{* * *}$ & $-60.88^{* * *}$ \\
Output $^{\mathrm{b}}$ & $-16.99^{* * *}$ & $-156.65^{* * *}$ & & $-16.96^{* * *}$ & $-156.51^{* * *}$ \\
Price $^{\mathrm{b}}$ & $-12.40^{* * *}$ & $-60.55^{* * *}$ & & $-12.38^{* * *}$ & $-60.31^{* * *}$ \\
\hline
\end{tabular}

Notes: a: In first difference.

b: In second difference.

* indicates the level of significance at $10 \%$.

** indicates the level of significance at $5 \%$.

*** indicates the level of significance at $1 \%$.

The critical values are gathered from Mackinnon (1996) and are one-sided $p$-values. 
data were supplemented with overnight interest data from the EDDS and the Borsa İstanbul (BIST) database. Table A.1 (in the appendix) provides the definitions and sources of the variables. We used 11 monthly dummies to account for seasonality. We included intercept dummies to account for the financial crises from February 1994 to June 1994 and from November 2000 to March 2001.

\section{Methodology}

We employ Kilian and Vigfusson's (2011) methodology to examine the asymmetric effect of monetary policy on economic activity. The nonlinear VAR $(p)$ model that we consider is the following:

$$
\begin{aligned}
i_{t}= & b_{10}+\sum_{k=1}^{p} b_{11, k} i_{t-k} \\
& +\sum_{k=1}^{p} b_{12, k} \lambda_{t-k}+\varepsilon_{1, t}, \text { where } \\
t= & 1,2, \ldots, T \\
\lambda_{t}= & b_{20}+\sum_{k=1}^{p} b_{21, k} i_{t-k}+\sum_{k=1}^{p} b_{22, k} \lambda_{t-k} \\
& +\sum_{k=1}^{p} g_{21, k} i^{+}{ }_{t-k}+\varepsilon_{2, t}, \text { where } \\
t= & 1,2, \ldots, T
\end{aligned}
$$

where $p$ is the lag order, $i_{t}$ is the change in interest rate and $\lambda_{t}$ is the column vector of the macroeconomic variables - exchange rate, output and inflation. Equation 1 is the standard (symmetric) linear model in $i_{t}$ and $\lambda_{t}$, but Equation 2 includes both interest rate change and the censored variable of $i_{t}$ $\left(i_{t}^{+}\right)$. The censored variable $i_{t}^{+}$is for the positive changes in interest rate, which can be defined as

$$
i_{t}^{+}= \begin{cases}i_{t}, & \text { if } i_{t}>0 \\ 0, & \text { if } i_{t} \leq 0\end{cases}
$$

$b_{10}$ and $b_{20}$ in Equations 1 and 2 are for the column vector of the intercept term and the dummy variables, respectively. $b_{11}$ and $b_{21}$ are the column vectors of the coefficients of the interest rate change. $b_{12}$ and $b_{22}$ comprise the matrix of the coefficients of the macroeconomic variables. $g_{21}$ is a column vector of the coefficient of the censored variable. $\varepsilon_{1, t}$ and $\varepsilon_{2, t}$ stand for the residual vectors.
In order to make inferences, we gather the orthogonalized shocks to the variables by using the Cholesky decomposition. Later, we apply a version of the Kilian and Vigfusson (2011) methodology to compute nonlinear impulse responses to positive and negative interest rate shocks. The impulse responses are constructed by including a data generating process (DGP) under the working hypothesis that the data are generated regardless of whether the true DGP is symmetric or asymmetric, and by combining Equation 1 (interest rate change coefficient and residuals) and Equation 2 (other variables' coefficients and residuals). Because of the linear nature of Equation 1, the initial impact of a shock on interest rate is a shock to itself, regardless of whether the nature of the shock is positive or negative are the same.

In order to assess the effect of monetary policy on economic performance, we need to identify the stance of monetary policy, which is not an easy task. The monetary authority sets its policy tools by considering the state of the economy as well as the authority's intention to set up monetary policy changes. By following Christiano, Eichenbaum and Evans (1999) and the reference cited therein, we specify a VAR model and identify the monetary policy shocks. Since we use the Cholesky decomposition, the order of variables is important. In the specification, the variables are ordered such that the first variable affects all the remaining variables but cannot respond contemporaneously to any variable in the system (within the month); the second variable can respond contemporaneously to the first variable but cannot be affected by the previous (first) variable. The last variable is affected by all the preceding variables contemporaneously but can affect none of the preceding variables. However, all the variables affect each other with a lag. We model the system such that policy rate, which is the CBRT's main policy tool, is adjusted with currency fluctuations. Moreover, policy rate affects output and prices. Therefore, our variables' order is exchange rate, interest rate, industrial production and prices (for ordering of variables, see Christiano, Eichenbaum and Evans [1999], Kamin and Rogers [2000] and Berument and Pasaogullari [2003]).

Before estimating the model, we test for the presence of asymmetry. Following Kilian and Vigfusson (2011), we employ two asymmetry tests: a slopebased test and an impulse-response-based test. 
Table 2. Slope-based asymmetry test.

\begin{tabular}{lll}
\hline & \multicolumn{1}{c}{ F-test } & $p$-Value \\
\hline Exchange rate & 0.0692993 & 0.99664 \\
Output & 0.76097 & 0.57861 \\
Prices & 0.676644 & 0.521492 \\
\hline
\end{tabular}

For the slope-based test, Equation 2 is estimated, then the null hypothesis that $H_{0}: g_{21,0}=\ldots \ldots \ldots=$ $g_{21, \mathrm{p}}=0$ against $\mathrm{Ha}$ : not $\mathrm{Ho}$ is tested. Table 2 reports the slope-based test statistics for each macroeconomic variable that is considered in vector $\lambda_{t}$. According to these statistics, we cannot reject the null hypothesis, which is that the coefficient of the censored variable is zero. Therefore, we cannot report the presence of asymmetry for these three variables.

Although slope-based tests are useful to determine asymmetry, they do not give any information about its direction and level. In order to account for those, we also employ an impulse-response-based test. Based on the gathered impulse responses, we calculate the impacts of the positive and negative interest rate change shocks, The impacts of both types of shocks in the same period are compared and tested statistically to determine whether they are the same or not. In these tests, the null hypothesis is

$$
\begin{aligned}
& H_{0}: \mathrm{I}_{y}(h, \delta)=-\mathrm{I}_{y}(h,-\delta) \text { or } \\
& H_{0}: \mathrm{I}_{y}(h, \delta)+\mathrm{I}_{y}(h,-\delta)=0 \\
& H a: \text { not Ho }
\end{aligned}
$$

$I_{y}(h, \delta)$ and $I_{y}(h,-\delta)$ are the responses of $\lambda_{t}$ and interest rates at period $h=1,2, \ldots H$ to shock $\delta$. This test has an asymptotic $\chi_{H+1}^{2}$ distribution and it depends on the impact of the shock. Therefore, the impulseresponse-based test is more relative and powerful than the slope-based test (Kilian and Vigfusson 2009). Table 3 suggests that the asymmetric effects of tight and loose monetary policy shocks on output and prices are statistically significant under large shocks. Thus, the impulse-response-based tests support asymmetry for output and prices.

\section{Empirical results}

Economic theory suggests that a tight monetary policy decreases exchange rate (appreciation of domestic currency) and prices and does not increase output level (see, for example, Kim and Roubini [2000] and Berument [2007]). Moreover, nonlinear models suggest that tight monetary policy has an effect on output, while loose monetary policy has a limited effect (Cover 1992; Morgan 1993; and Garibaldi 1997). Therefore, it might be expected that a tight monetary policy decreases exchange rate and inflation and has more effect than a loose policy on macroeconomic variables for an emerging open economy such as Turkey.

Figure 1 reports the impulse responses for eight periods when different sizes (1-, 2- and 3-SD shocks) and natures (positive and negative) of shocks are given to interest rate. The solid lines show the impulse responses to a positive shock (tight monetary policy) and the dashed lines show the impulse responses to a negative shock (loose monetary policy). The first column reports the responses of interest rate, exchange rate, industrial production and inflation to a 1-SD shock to interest rate. The second column shows the responses to a 2-SD shock and the last column shows the responses to a 3-SD shock. The responses to negative interest rate shocks are reported as their mirror images to facilitate the comparison of magnitudes. Here, because of the

\begin{tabular}{|c|c|c|c|c|c|c|c|c|c|c|c|c|}
\hline \multirow[b]{2}{*}{ Period } & \multicolumn{3}{|c|}{ Exchange rate } & \multicolumn{3}{|c|}{ Interest rate } & \multicolumn{3}{|c|}{ Output } & \multicolumn{3}{|c|}{ Prices } \\
\hline & $\begin{array}{c}1-S D \\
\text { shock }\end{array}$ & $\begin{array}{l}\text { 2-SD } \\
\text { shock }\end{array}$ & $\begin{array}{c}\text { 3-SD } \\
\text { shock }\end{array}$ & $\begin{array}{l}1-S D \\
\text { shock }\end{array}$ & $\begin{array}{c}2-S D \\
\text { shock }\end{array}$ & $\begin{array}{l}\text { 3-SD } \\
\text { shock }\end{array}$ & $\begin{array}{c}1-S D \\
\text { shock }\end{array}$ & $\begin{array}{l}\text { 2-SD } \\
\text { shock }\end{array}$ & $\begin{array}{c}\text { 3-SD } \\
\text { shock }\end{array}$ & $\begin{array}{c}1-S D \\
\text { shock }\end{array}$ & $\begin{array}{l}\text { 2-SD } \\
\text { shock }\end{array}$ & $\begin{array}{c}\text { 3-SD } \\
\text { shock }\end{array}$ \\
\hline 1 & 0 & 0 & 0 & 0 & 0 & 0 & 0.01 & 2.2 & $8.13^{* * *}$ & 0 & 0.1 & 0.37 \\
\hline 2 & 0 & 0.19 & 0.84 & 0 & 0.06 & 0.2 & 0.01 & 2.35 & $8.9^{* *}$ & 0 & 0.65 & 2.47 \\
\hline 3 & 0 & 0.48 & 1.76 & 0 & 0.13 & 0.67 & 0.02 & 2.72 & $10.08^{* *}$ & 0.01 & 3.12 & $11.51^{* * *}$ \\
\hline 4 & 0.01 & 2.18 & 7.03 & 0.01 & 1.96 & 6.32 & 0.02 & 3.14 & $11.57^{* *}$ & 0.02 & 3.6 & $13.23^{* *}$ \\
\hline 5 & 0.02 & 2.84 & $9.32^{*}$ & 0.02 & 2.83 & $9.32^{*}$ & 0.02 & 3.48 & $12.98^{* *}$ & 0.02 & 3.91 & $14.52^{* *}$ \\
\hline 6 & 0.02 & 3 & 9.99 & 0.02 & 3.02 & 10.21 & 0.02 & 3.66 & $13.68^{* *}$ & 0.02 & 3.93 & $14.65^{* *}$ \\
\hline 7 & 0.02 & 3.19 & 11.1 & 0.02 & 3.08 & 10.6 & 0.02 & 3.81 & $14.26^{* *}$ & 0.03 & 3.96 & $14.79^{* *}$ \\
\hline 8 & 0.02 & 3.3 & 11.63 & 0.02 & 3.58 & 13.17 & 0.02 & 3.85 & $14.41^{*}$ & 0.03 & 4.01 & $14.95^{*}$ \\
\hline
\end{tabular}
linear nature of Equation 1, the contemporaneous

Table 3. Impulse-response-based asymmetry tests.

Notes: Based on 20000 simulations of model $x^{2}$ values.

* indicates the level of significance at $10 \%$.

** indicates the level of significance at $5 \%$.

*** indicates the level of significance at $1 \%$. 

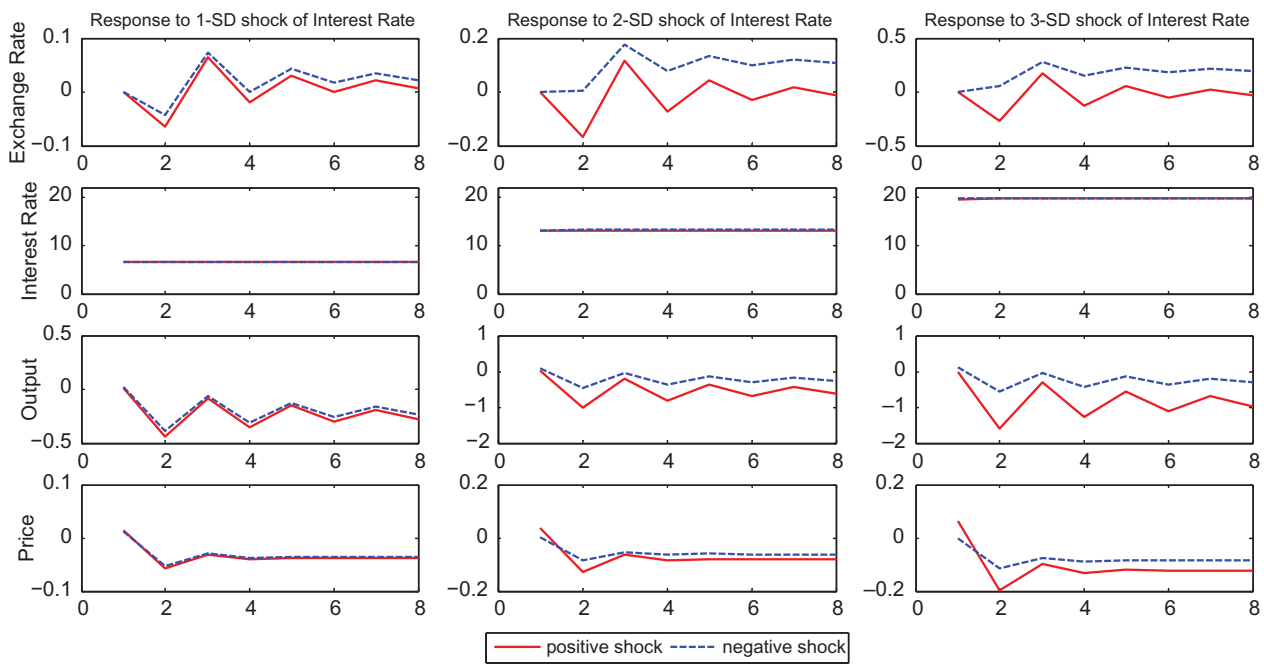

Figure 1. Impulse responses to 1-, 2- and 3-SD positive and negative interest rate change shocks to the base model. Note: The responses to negative shocks are shown as mirror images to facilitate the comparison.

effects of positive and negative shocks on interest rate are the same; however, due to Equation 2, the contemporaneous effects of interest rate shocks on other variables are not asymmetric. Moreover, due to the feed-in mechanism, after the first period, the responses for interest rate are asymmetric.

The first column suggests that a positive 1-SD shock to interest rate decreases output, prices and exchange rate (appreciates domestic currency) instantaneously. The effects on output and prices are persistent. Moreover, the effects of a negative interest rate shock, which are reported as their mirror images, are almost the same as the effects of a positive shock. On the other hand, the effects of a positive shock on output and exchange are slightly comparable to those of a negative shock.

The second column reports the impulse responses when the 2-SD positive and negative shocks are given. The positive interest rate shock decreases exchange rate, output and prices, similar to the first column. The negative interest rate shock does not depreciate local currency as much, and appreciation occurs after the second period, with the magnitude of appreciation higher than that of depreciation. Tight monetary policy is associated with lower prices and loose monetary policy is associated with higher prices. However, a 2-SD positive shock decreases prices more than an increase in prices does from a 2-SD negative shock on interest rates. The exchange rate response is unexpected and the response of output and prices to a loose monetary policy is lower than to a tight one.
Therefore, the asymmetric effect of monetary policy is clearly observed.

The third column repeats the exercise with the 3SD positive and negative shocks. The results are similar to the 2-SD shocks but are more visible. When we compare these three conditions, we observe that (1) in all three conditions the shock to interest rate is persistent and that the tight and loose monetary actions' effects are symmetric; (2) the effect of tight monetary policy on exchange is higher in the first two periods and there is asymmetry; (3) for the output responses, tight monetary policy seems more effective than loose monetary policy; (4) the effect of a tight monetary policy shock on price is more effective after the first period (this is more pronounced in the 2- and 3-SD shocks); and (5) the higher is the magnitude of the shock, the higher will be the degree of asymmetry. Consequently, the asymmetric effects of tight and loose monetary shocks are captured under medium (2-SD) and large (3-SD) shocks on all variables.

Identifying monetary policy with the VAR methodology is often criticized due to the well-established puzzles that impulse response functions produce, such as unexpected changes in price, exchange rate and liquidity when a shock is introduced to interest rates. In our analysis, all the variables respond to monetary policy shocks in such a way that they do not produce the above puzzles. However, the exchange rate puzzle is observed after the third period. 


\section{Robustness check}

To ensure the robustness of our findings, we repeat the analysis for the subsamples 1996-2014 (with the 1994 financial crisis eliminated) (Fig. 2) and 20032010 (after the 2002 financial crisis and before the 2011 crisis) (Fig. 3). These results indicate that the full sample results are largely robust. For both subsamples, the exchange rate puzzle disappears. As economic theory suggests, tight monetary policy approximates the local currency but loose monetary policy depreciates the local currency. Both figures suggest that tight monetary policy is more effective than loose monetary policy on exchange rate. Moreover, the evidence for prices is robust; however, the evidence for output is mixed.

\section{Caveats}

There is a set of literature regarding how the asymmetric effects of monetary policy depends on the state of the economy (see, for example, Garcia and Schaller [2002], Dolado and Maria-Dolores [2001, 2006], Peersman and Smets [2002], Kaufmann [2002] and Tan and Habibullah
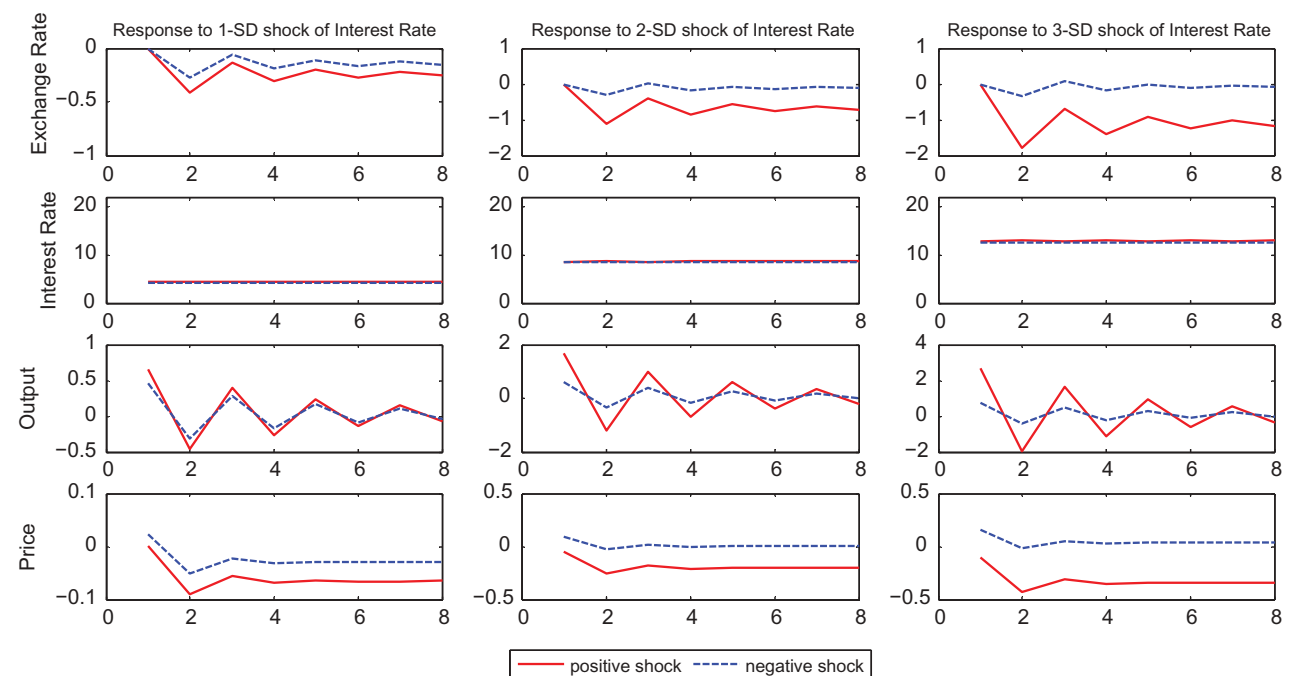

Figure 2. Impulse responses to 1-, 2- and 3-SD positive and negative interest rate change shocks to the base model from January 1996 to July 2014.

Note: The responses to negative shocks are shown as mirror images to facilitate the comparison.
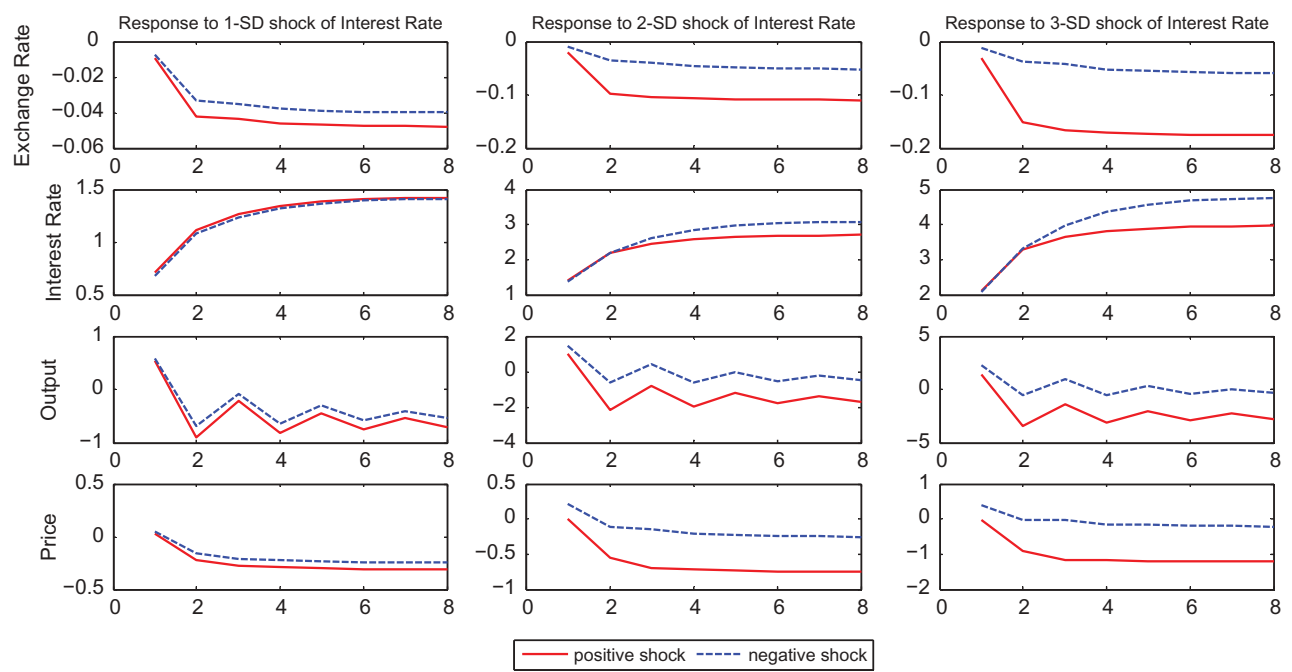

Figure 3. Impulse Responses to 1-, 2- and 3-SD positive and negative interest rate change shocks to the base model from January 2003 to December 2010.

Note: The responses to negative shocks are shown as mirror images to facilitate the comparison. 
[2007]). There are no official business cycle turning points for Turkey; however, Alp, Baskaya, Kilinc and Yuksel $(2012,47)$ identify that recession periods are low for the period we consider. In Turkey, mid-1994 to mid-1998 and mid-2001 to late-2008 might be considered boom periods. Thus, a bigger part of our sample period falls into boom periods and one may interpret our findings within a boom period for Turkey. The three periods of recession noted by Alp et al. do not allow us to assess the effect of monetary policy during recession periods.

\section{Conclusion}

In this study, we investigate how the stance of monetary policy affects economic performance by employing a nonlinear VAR model. The results indicate that tight monetary policy appreciates domestic currency and decreases output in an emerging open economy and that a tight monetary policy is more effective for exchange rate and output than a loose change to monetary policy. Moreover, the magnitude of asymmetry is bigger for exchange rate and output when the shock to interest rate is bigger.

\section{Acknowledgements}

The authors would like to thank Rana Nelson for her helpful comments.

\section{Disclosure statement}

No potential conflict of interest was reported by the authors.

\section{References}

Alp, H., Y. S. Baskaya, M. Kilinc, and C. Yuksel. 2012. "Stylized Facts for Business Cycles in Turkey." Working Paper No. 1202. Research and Monetary Policy Department, Central Bank of the Republic of Turkey.

Ball, L., and N. G. Mankiw. 1994. "Asymmetric Price Adjustment and Economic Fluctuations." The Economic Journal 104 (423): 247. doi:10.2307/2234746.

Ball, L., and D. Romer. 1989. "Are Prices Too Sticky?" The Quarterly Journal of Economics 104 (3): 507. doi:10.2307/ 2937808.

Ball, L., and D. Romer. 1990. "Real Rigidities and the NonNeutrality of Money." The Review of Economic Studies 57 (2): 183. doi:10.2307/2297377.
Bernanke, B., and M. Gertler. 1986. Agency Costs, Collateral, and Business Fluctuations. No. w2015. Cambridge, MA: National Bureau of Economic Research. http://www.nber. org/papers/w2015.pdf

Berument, H. 2007. "Measuring Monetary Policy for a Small Open Economy: Turkey." Journal of Macroeconomics 29 (2): 411-430. doi:10.1016/j.jmacro.2006.02.001.

Berument, H. M., and M. Pasaogullari. 2003. "Effects of the Real Exchange Rate on Output and Inflation: Evidence from Turkey." The Developing Economies 41 (4): 401-435. doi:10.1111/j.1746-1049.2003.tb01009.x.

Caballero, R., and E. M. R. A. Engel. 1992. Price Rigidities, Asymmetries, and Output Fluctuations. No. w4091. Cambridge, MA: National Bureau of Economic Research. http://www.nber.org/papers/w4091.pdf

Christiano, L. J., M. Eichenbaum, and C. L. Evans. 1999. "Monetary Policy Shocks: What Have We Learned and to What End?" In Handbook of Macroeconomics (Chapter 2), Vol. 1, edited by J. B. Taylor and M. Woodford, 65-148. North-Holland: Elsevier. doi:10.1016/S1574-0048(99)01005-8.

Cover, J. P. 1992. "Asymmetric Effects of Positive and Negative Money-Supply Shocks." The Quarterly Journal of Economics 107 (4): 1261-1282. doi:10.2307/2118388.

DeLong, J. B., and L. H. Summers. 1988. "How Does Macroeconomic Policy Affect Output?" Brookings Papers on Economic Activity 1988 (2): 433-494. doi:10.2307/ 2534535.

Dolado, J., and R. Maria-Dolores. 2006. "State Asymmetries in the Effects of Monetary Policy Shocks on Output: Some New Evidence for the Euro-Area." Nonlinear Time Series Analysis of Business Cycles 276: 311-331.

Dolado, J. J., and R. María-Dolores. 2001. “An Empirical Study of the Cyclical Effects of Monetary Policy in Spain (1977-1997).” Investigaciones Economicas 25 (1): 3-30.

Friedman, F. 1968. “The Role of Monetary Policy.” American Economic Review 58 (1): 1-17.

Garcia, R., and H. Schaller. 2002. "Are the Effects of Monetary Policy Asymmetric?” Economic Inquiry 40 (1): 102-119. doi:10.1093/ei/40.1.102.

Garibaldi, P. 1997. "The Asymmetric Effects of Monetary Policy on Job Creation and Destruction." Staff Papers - International Monetary Fund 44 (4): 557. doi:10.2307/3867466.

Georgiadis, G. 2015. "Examining Asymmetries in the Transmission of Monetary Policy in the Euro Area: Evidence from a Mixed Cross-Section Global VAR Model." European Economic Review 75: 195-215. doi:10.1016/j.euroecorev.2014.12.007.

Kamin, S. B., and J. H. Rogers. 2000. "Output and the Real Exchange Rate in Developing Countries: An Application to Mexico." Journal of Development Economics 61 (1): $85-$ 109. doi:10.1016/S0304-3878(99)00062-0.

Karras, G. 2013. "Asymmetric Effects of Monetary Policy with or without Quantitative Easing: Empirical Evidence for the US." The Journal of Economic Asymmetries 10 (1): 1-9. doi:10.1016/j.jeca.2013.04.001. 
Karras, G., and H. H. Stokes. 1999. "Why are the Effects of Money-Supply Shocks Asymmetric? Evidence from Prices, Consumption, and Investment." Journal of Macroeconomics 21 (4): 713-727. doi:10.1016/S0164-0704(99)80003-2.

Kaufmann, S. 2002. "Is There an Asymmetric Effect of Monetary Policy over Time? A Bayesian Analysis Using Austrian Data." Empirical Economics 27 (2): 277-297. doi:10.1007/s001810100099.

Kilian, L., and R. J. Vigfusson. 2009. "Pitfalls in Estimating Asymmetric Effects of Energy Price Shocks." SSRN Electronic Journal. doi:10.2139/ssrn.1420252.

Kilian, L., and R. J. Vigfusson. 2011. "Are the Responses of the U.S. Economy Asymmetric in Energy Price Increases and Decreases? Are Responses of the U.S. Economy Asymmetric?" Quantitative Economics 2 (3): 419-453. doi:10.3982/QE99.

Kim, S., and N. Roubini. 2000. "Exchange Rate Anomalies in the Industrial Countries: A Solution with A Structural VAR Approach.” Journal of Monetary Economics 45 (3): 561-586. doi:10.1016/S0304-3932(00)00010-6.

Lo, M. C., and J. M. Piger. 2005. "Is the Response of Output to Monetary Policy Asymmetric? Evidence from a Regime-Switching Coefficients Model.” Journal of Money, Credit, and Banking 37 (5): 865-886. doi:10.1353/ mcb.2005.0054.

MacKinnon, J. G. 1996. "Numerical Distribution Functions for Unit Root and Cointegration Tests." Journal of Applied Econometrics 11: 601-618.

Morgan, D. P. 1993. "Asymmetric Effects of Monetary Policy.” Economic Review 78 (Q II): 21-33.

Peersman, G., and F. Smets 2002. "Are the Effects of Monetary Policy in the Euro Area Greater in Recessions than in Booms?" In Monetary Transmission in
Diverse Economies, edited by L. Mahadeva and P. Sinclair, 28-48. Cambridge: Cambridge University Press. http:// ebooks.cambridge.org/ref/id/CBO9780511492488A012.

Ravn, M. O., and M. Sola. 1996. "A Reconsideration of the Empirical Evidence on the Asymmetric Effects of MoneySupply shocks: Positive vs. Negative or Big vs. Small?" SSRN Electronic Journal. doi:10.2139/ssrn.56134.

Rhee, W., and R. W. Rich. 1995. "Inflation and the Asymmetric Effects of Money on Output Fluctuations." Journal of Macroeconomics 17 (4): 683-702. doi:10.1016/ 0164-0704(95)80089-1.

Shen, C.-H. 2000. "Are the Effects of Monetary Policy Asymmetric? The Case of Taiwan." Journal of Policy Modeling 22 (2): 197-218. doi:10.1016/S0161-8938(98) 00025-8.

Sznajderska, A. 2014. "Asymmetric Effects in the Polish Monetary Policy Rule.” Economic Modelling 36: 547-556. doi:10.1016/j.econmod.2013.09.045.

Tan, S.-H., and M. S. Habibullah. 2007. "Business Cycles and Monetary Policy Asymmetry: An Investigation Using Markov-Switching Models." Physica A: Statistical Mechanics and Its Applications 380: 297-306. doi:10.1016/j.physa.2007.02.063.

Vašíček, B. 2012. "Is Monetary Policy in the New EU Member States Asymmetric?" Economic Systems 36 (2): 235-263. doi:10.1016/j.ecosys.2011.07.003.

Weise, C. L. 1999. "The Asymmetric Effects of Monetary Policy: A Nonlinear Vector Autoregression Approach." Journal of Money, Credit and Banking 31 (1): 85. doi:10.2307/2601141.

Zakir, N., and W. S. Malik. 2013. "Are the Effects of Monetary Policy on Output Asymmetric in Pakistan?" Economic Modelling 32: 1-9. doi:10.1016/j.econmod.2013.01.037.

\section{Appendix}

Table A.1. Data sources.

\begin{tabular}{|c|c|c|c|}
\hline Variable & Definition & Code & Source \\
\hline Exchange rate basket* & 0.5 USD + 0.5 EUR & TP.DK.EUR.S.YTL.1 & Authors' calculation \\
\hline USD & $\begin{array}{l}\text { USD/TRY exchange rate, selling } \\
\text { prices }\end{array}$ & TP.DK.USD.S.YT L.1 & CBRT, EDDS \\
\hline EUR & $\begin{array}{l}\text { EUR/TRY exchange rate, selling } \\
\text { prices }\end{array}$ & & CBRT, EDDS \\
\hline Interest rate $\mathrm{e}^{* *}$ & $\begin{array}{l}\text { Simple interest rate weighted average (\%) (overnight) between } \\
1990 \text { and } 2000 \text { from CBRT } \\
2000-2014 \text { from BIST }\end{array}$ & TP.PY.P06.ON & CBRT, EDDS and BIST \\
\hline Output** & $\begin{array}{l}\text { Industrial production }(2010=100)^{* *} \\
\text { January } 1990 \text { to April } 2000 \\
\text { May } 2000 \text { to December } 2004 \\
\text { January } 2005 \text { to July } 2014\end{array}$ & $\begin{array}{l}\text { TP.UR4.U01 } \\
\text { TP.TSY01 } \\
\text { TP.N2SY01 }\end{array}$ & CBRT, EDDS \\
\hline Prices** & $\begin{array}{l}\text { General consumer price index based on }(2003=100) \\
\text { January } 1990 \text { to December } 2002(1987=100) \\
\text { January } 2003 \text { to July } 2014(2003=100)\end{array}$ & $\begin{array}{l}\text { TP.FG.A01 } \\
\text { TP.FG.J0: } 0\end{array}$ & CBRT, EDDS \\
\hline
\end{tabular}

Notes: CBRT, Central Bank of the Republic of Turkey; EDDS, electronic data delivery system; BIST: Borsa Istanbul; REER, real exchange rate; USD, United States Dollar; TRY, New Turkish Lira (six zeros dropped).

* Authors' calculation.

${ }^{* *}$ A combination of the given series is used for the entire period. 